\title{
Spatial Dynamic Variations of Regional Inequality in Korea and Japan
}

\author{
Soon-Sung LEE
}

\begin{abstract}
This study attempts to illustrate the patterns of regional inequality and their dynamic variations in Korea and Japan where economic development levels differ. In order to present a reasonable demonstration of such patterns, the study starts with and further develops Williamson' $\mathrm{s}$ inverted-U hypothesis and Amos' augmented inverted-U hypothesis through a detailed empirical analysis of the interplay between regional dynamics and regional income inequality in the cases of both Korea and Japan. The primary conclusions of this study can be stated as: (1) Korea and Japan are moving into the spatial restructuring phase from the preceding polarization reversal phase after 1996 and 1978, respectively; (2) Regional dynamics applied to widespread regional growth and decline becomes very clear by portraying of the dynamic variation of inequality in geographical space.
\end{abstract}

Keywords: regional inequality variations, Amos' augmented inverted-U, regional dynamics, decomposition of Theil entropy measure, expansions of rank-size function

\section{Introduction}

This study has two purposes. One is to discover the correlation between economic development and regional inequality by comparing the patterns of regional inequality in Korea and Japan. The other is to elucidate spatial dynamics originating in the variations of regional inequality in both countries. To these ends, it uses the augmented inverted-U hypothesis proposed by Amos [2] who explains increases in regional inequality at advanced phases of development. Further, it also applies the constructive method consisting of modified information theoretic measures and expanded rank-size functions used by Fan and Casetti [6].

Regional inequality is one of the most important themes in regional economics and regional policy. On these topics, discussions about the influence of economic development on regional inequality have taken place since 1950s. Kuznets [11] proposed the inverted-U hypothesis to investigate income inequality among individuals. Williamson [16] applied this hypothesis to demonstrate changes in regional inequality, and showed that regional inequality within nations exhibits the inverted-U pattern. ${ }^{1}$ Nevertheless, a new trend of increasing regional inequality in many developed nations during late 1970s and the 1980s exposed predictive and explanatory limits of inverted-U hypothesis (see Alonso [1], Amos [2], Coughlin and Mandelbaum [4], Fan and Casetti [6].) ${ }^{2)}$ Amos [2] developed Williamson's inverted-U by proposing the augmented inverted- $U$ hypothesis to explain increases in

Graduate School of Economics, Chuo University, 742-1 Higashinakano, Hachioji-shi, Tokyo, 192-0393, Japan 
regional inequality at advanced phases of development. Byun [3] recently analyzed the patterns of regional inequality in US and Korea where economic development levels differ. Fan and Casetti [6] focused on the subtle correlation between regional dynamics and regional income inequality rather than systemic inequality and clarified spatial and temporal dynamics of regional inequality in US.

Based on these theoretical underpinnings, this study compares regional inequality patterns in Korea and Japan that have not been studied yet. Since economic development levels differ in the two countries, in order to investigate the influence of economic development on regional inequality, it is necessary to study regional inequality in both countries. Then, this study highlights the large-scale regions generating inequality by elucidating spatial dynamic variations originating in the variations of regional inequality. ${ }^{3)}$

This paper is organized as follows. Section 2 explains the selected data and methodology. Section 3 examines the patterns of regional inequality in both countries. Section 4 shows the relations between spatial dynamic variations and regional income inequality. Section 5 gives concluding remarks.

\section{Data and methodology}

In this paper, Major City \& Province level is adopted in Korea as the geographic division used for this empirical analysis. Thus, 13 major cities \& provinces are selected ${ }^{4}$ for Korea while in the case of Japan, 47 prefectures are used as their counterpart.

As regards selected data in both countries, per capita GRDP (Gross Regional Domestic Product) is adopted as an index of regional income level.5) Such data is obtainable from Economic and Social Research Institute Cabinet Office, Government of Japan and Korea National Statistical Office's HP (http:kosis.nso.go.kr/). To focus on the process moving into the spatial restructuring phase from the polarization reversal phase, the period of analysis selected for Korea is from 1985 to 1999, while for Japan it is from 1970 to 1999.6)

This study uses coefficient of variation and Theil entropy measure to examine the patterns of regional inequality. Then, in order to clarify the spatial dynamic variations of inequality, this study attempts to decompose Theil entropy measure and to expand rank-size functions.

\section{Patterns of regional inequality}

In this section, based on Amos's augmented inverted- $\mathrm{U}^{7)}$, we examine the patterns of regional inequality in both countries. Systemic inequality is very critical to a comprehensive research of inter-regional inequality, as regional divergence and regional convergence are in fact closely associated with high or low level systemic inequality respectively.

General measures of inequality, such as coefficient of variation and Theil entropy measure, can be used to analyze systemic inequality. Systemic inequality levels of Korea and Japan by coefficient of variation and Theil entropy measure are shown in Table 1 and Table 2.

Table 1 shows the decreases of inter-regional inequality in Korea from 1985 to 1996 and increases after 1996, while Table 2 shows decreases of inter-regional inequality in Japan from 1970 to 1978, increases from 1978 to 1990 and re-decreases after 1990. If the patterns in both 
Table 1 Systemic inequality in Korea

\begin{tabular}{c|cccc|c|ccccc}
\hline Year & C. V. & $T(\%)$ & $\beta$ & $R^{2}$ & Year & C. V. & $T(\%)$ & $\beta$ & $R^{2}$ \\
\hline 1985 & 0.179 & $0.0156(0.42)$ & -0.229 & 0.94 & 1993 & 0.167 & $0.0137(0.37)$ & -0.210 & 0.88 \\
1986 & 0.185 & $0.0166(0.45)$ & -0.235 & 0.95 & 1994 & 0.175 & $0.0149(0.40)$ & -0.219 & 0.90 \\
1987 & 0.183 & $0.0162(0.44)$ & -0.232 & 0.96 & 1995 & 0.175 & $0.0147(0.40)$ & -0.216 & 0.90 \\
1988 & 0.180 & $0.0156(0.42)$ & -0.229 & 0.95 & 1996 & 0.166 & $0.0135(0.36)$ & -0.207 & 0.88 \\
1989 & 0.175 & $0.0149(0.40)$ & -0.223 & 0.94 & 1997 & 0.173 & $0.0147(0.40)$ & -0.217 & 0.87 \\
1990 & 0.178 & $0.0154(0.41)$ & -0.227 & 0.94 & 1998 & 0.189 & $0.0175(0.47)$ & -0.237 & 0.88 \\
1991 & 0.184 & $0.0164(0.44)$ & -0.234 & 0.94 & 1999 & 0.199 & $0.0194(0.52)$ & -0.253 & 0.89 \\
1992 & 0.187 & $0.0167(0.45)$ & -0.232 & 0.92 & & & & & & \\
\hline
\end{tabular}

Note: C. V. is coefficient of variation (C. V. $=\sigma / \mu$, in which $\sigma$ is standard deviation of per capita GRDP, $\mu$ is mean of per capita GRDP), $T$ is Theil entropy measure (see Eq. (3)), (\%) is Theil measure as a percentage of maximum inequality ; here maximum inequality $=\log _{2}$ $13=3.70$ bits, $\beta$ is estimate of rank-size function (the slope coefficient), $R^{2}$ is the coefficient of determination for estimating rank-size function.

Table 2 Systemic inequality in Japan

\begin{tabular}{c|cccc|c|ccccc}
\hline Year & C. V. & $T(\%)$ & $\beta$ & $R^{2}$ & Year & C. V. & $T(\%)$ & $\beta$ & $R^{2}$ \\
\hline 1970 & 0.260 & $0.0316(0.57)$ & -0.265 & 0.91 & 1985 & 0.208 & $0.0193(0.35)$ & -0.196 & 0.90 \\
1971 & 0.242 & $0.0272(0.49)$ & -0.245 & 0.91 & 1986 & 0.215 & $0.0203(0.37)$ & -0.200 & 0.91 \\
1972 & 0.230 & $0.0244(0.44)$ & -0.231 & 0.94 & 1987 & 0.221 & $0.0211(0.38)$ & -0.201 & 0.90 \\
1973 & 0.219 & $0.0220(0.40)$ & -0.219 & 0.95 & 1988 & 0.232 & $0.0232(0.42)$ & -0.212 & 0.91 \\
1974 & 0.204 & $0.0189(0.34)$ & -0.202 & 0.93 & 1989 & 0.237 & $0.0239(0.43)$ & -0.212 & 0.90 \\
1975 & 0.186 & $0.0159(0.29)$ & -0.184 & 0.92 & 1990 & 0.240 & $0.0245(0.44)$ & -0.216 & 0.91 \\
1976 & 0.188 & $0.0163(0.29)$ & -0.188 & 0.92 & 1991 & 0.234 & 0.0238 & $(0.43)$ & -0.217 & 0.91 \\
1977 & 0.185 & $0.0158(0.28)$ & -0.182 & 0.91 & 1992 & 0.221 & 0.0214 & $(0.39)$ & -0.204 & 0.90 \\
1978 & 0.183 & $0.0154(0.28)$ & -0.180 & 0.92 & 1993 & 0.212 & 0.0196 & $(0.35)$ & -0.194 & 0.89 \\
1979 & 0.187 & $0.0161(0.29)$ & -0.186 & 0.93 & 1994 & 0.202 & $0.0179(0.32)$ & -0.185 & 0.89 \\
1980 & 0.189 & $0.0166(0.30)$ & -0.187 & 0.90 & 1995 & 0.204 & $0.0183(0.33)$ & -0.188 & 0.88 \\
1981 & 0.196 & $0.0173(0.31)$ & -0.189 & 0.90 & 1996 & 0.202 & $0.0182(0.33)$ & -0.190 & 0.90 \\
1982 & 0.199 & $0.0178(0.32)$ & -0.191 & 0.91 & 1997 & 0.202 & 0.0180 & $(0.32)$ & -0.187 & 0.88 \\
1983 & 0.205 & $0.0187(0.34)$ & -0.195 & 0.91 & 1998 & 0.195 & 0.0167 & $(0.30)$ & -0.178 & 0.88 \\
1984 & 0.202 & $0.0182(0.33)$ & -0.191 & 0.90 & 1999 & 0.191 & 0.0160 & $(0.29)$ & -0.174 & 0.87 \\
\hline
\end{tabular}

Note: Explanation of Table 2 is the same as Table 1, however maximum inequality $=\log _{2} 47=$ 5.55 bits.

countries are described graphically, they would appear as shown in Fig. 1. ${ }^{8)}$ As an increase of inter-regional inequality is shown again after 1996, Korea has passed the polarization reversal phase, and entered into spatial restructuring phase. Similarly, Japan moved into spatial restructuring after 1978, and a decrease of inter-regional inequality is seen again after 1990.

As another approach to measuring regional inequality, rank-size function has rarely been used in connection with inequality. The rank-size function put forth by Zipf [18] stands as the basic method in this study, which can evaluate relation between the size and rank in urban system. Its simplest representation is 


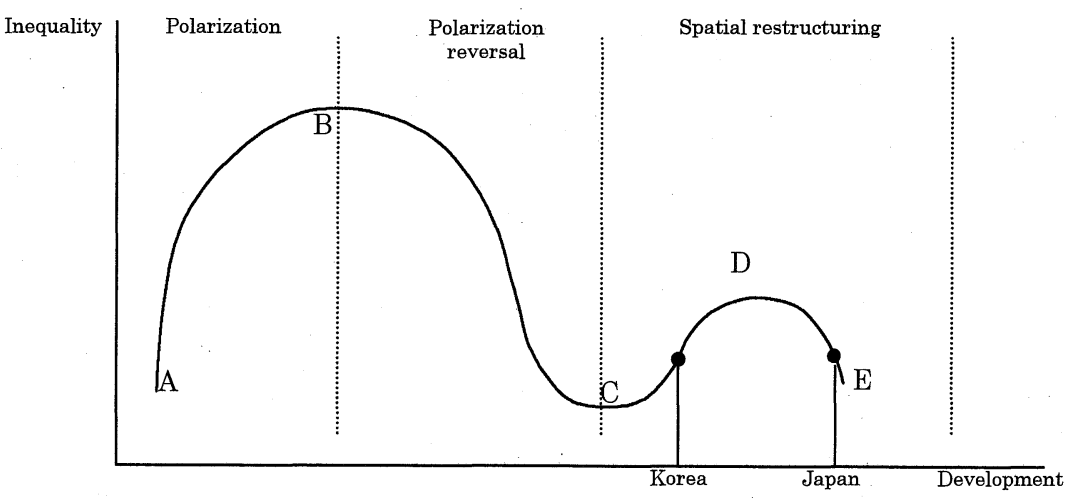

Fig. 1 The patterns of inter-regional inequality in Korea and Japan

$$
r^{n} S=M
$$

in which $S$ is the size, $r$ is the rank and $n, M$ are constants which change with countries and times. This function is mainly used to investigate concentration of population in an urban system, but in this paper, population $(S)$ is replaced by regional income $(S y)$. The natural logarithmic form of this relationship can also be expressed as in Eq. (2)

$$
\ln S_{y}=\alpha+\beta \ln r \quad(\alpha=\ln M, \beta=-n)
$$

in which $\beta$ is the slope coefficient of the rank-size curve. Parameter $\beta$ indicates the concentration level-high/low level corresponds to high/low level of systemic inequality -which also can be used as a measure of systemic inequality.

Here, the rank of a region is determined by its per capita GRDP, for example, $r=1$ for the highest per capita GRDP region, $r=2$ for the second highest per capita GRDP region, etc. The $\beta$ values, estimated from regression, are shown in Table 1 and Table 2 . The estimated $\beta$ values show the same tendency as the systemic measures reported above.

\section{Regional inequality variations}

Although the inequality measures mentioned above can show the levels of systemic inequality, they cannot explain inter-regional inequality variations in selected regions. Therefore, new analysis methods are required to overcome such deficiency. In the following sections, new modified Theil entropy measure and expanded rank-size function will be introduced to explain the detailed variations of inter-regional inequality.

\subsection{Inequality variations by decomposed Theil entropy measure}

Theil entropy measure can be expressed by Eq. (3), which can also be decomposed as Eq. $(4)$.

$$
\begin{gathered}
T=\sum_{i=1}^{n} w_{i} \log n w_{i} \\
=\sum_{g=1}^{G} W_{g} \log \frac{W_{g}}{n_{g} / n}+\sum_{g=1}^{G} W_{g}\left[\sum_{i \in g} \frac{w_{i g}}{W_{g}} \log \frac{w_{i g} / W_{g}}{1 / n_{g}}\right]
\end{gathered}
$$

where is the total number of regions, $n_{g}(g=1,2, \cdots, G)$ is the total number of regions in 
group $g . \quad w_{i}$ and $w_{i g}$ are the fraction of region $i$ 's per capita GRDP with respect to the sum of all regions' per capita GRDP $\left(=y_{i} / \sum y_{i}\right)$, and $W_{g}$ is the sum of all $w_{i g}$ 's in the group $g$. The first term on the RHS of Eq. (4) measures inter-group inequality ; and the second term measures intra-group inequality. With such decomposed Theil entropy measures, it is possible to interpret the inequality variations by dividing it as between and within regional groups.

As divisions of regional groups, one Capital metropolitan and three regional groups are set in Korea according to The 2nd Comprehensive National Territorial Plan, that is, the Capital metropolitan consists of Seoul, Incheon and Gyeonggi, the Central consists of Jeongbuk, Jeongnam and Gangwon, the Southeast consists of Busan, Daegu, Gyeongbuk and Gyeongnam, the Southwest consists of Jeonbuk, Jeonnam and Jeju, while in the case of Japan, its 10 regional groups in Grand Design for the 21st Century are reduced to 7 by combining Hokkaido-Tohoku, Hokuriku-Chubu and Kyushu-Okinawa together within the same group.

Table 3 and Table 4 present the results based on decomposed Eq. (4) and are plotted in Fig. 2. Both countries share a similarity that the level and proportion of intra-group inequality are higher than inter-group inequality, which indicates that majority of inequality exists within groups rather than between. In the case of Japan (See Fig. 2B), the same trends can be found either inter-group or intra-group inequality. However, examining the case of Korea in Fig. 2A, we note that though the level of inter-group inequality has continuously decreased after 1987, the level of intra-group inequality has increased greatly.

The intra-group inequality in Korea (Table 3) show that, the share of inequalities in the Southeast is the largest (around more than 80\%), although it generally has been declining after 1992, it indicates that the inequality among the Southeast cities and provinces is still serious. Table 4B for Japan shows that while Kanto has the largest share of inequalities

Table 3 Inter-group and intra-group inequalities in Korea

\begin{tabular}{l|ccc|cccc}
\hline & & & & \multicolumn{3}{|c}{ Shares (\%) in intra-group inequality } \\
\cline { 4 - 7 } Year & $\begin{array}{c}\text { Inter-group } \\
\text { inequality (\%) }\end{array}$ & $\begin{array}{c}\text { Intra-group } \\
\text { inequality (\%) }\end{array}$ & $\begin{array}{c}\text { Capital } \\
\text { Metropolitan }\end{array}$ & $\begin{array}{c}\text { Central } \\
\text { South } \\
\text { east }\end{array}$ & South west \\
\hline 1985 & $0.00599(38.3)$ & $0.0096(61.7)$ & 3.5 & 3.9 & 88.5 & 4.1 \\
1986 & $0.00730(44.1)$ & $0.0093(55.9)$ & 3.3 & 0.4 & 92.7 & 3.6 \\
1987 & $0.00751(46.5)$ & $0.0087(53.5)$ & 2.8 & 1.7 & 92.5 & 3.0 \\
1988 & $0.00653(41.9)$ & $0.0091(58.1)$ & 4.0 & 0.7 & 89.6 & 5.7 \\
1989 & $0.00496(33.4)$ & $0.0099(66.6)$ & 4.2 & 2.1 & 87.8 & 5.9 \\
1990 & $0.00651(42.4)$ & $0.0088(57.6)$ & 2.6 & 3.4 & 85.5 & 8.5 \\
1991 & $0.00533(32.5)$ & $0.0111(67.5)$ & 1.7 & 3.7 & 88.1 & 6.5 \\
1992 & $0.00335(20.1)$ & $0.0133(79.9)$ & 0.3 & 4.0 & 90.9 & 4.8 \\
1993 & $0.00224(16.3)$ & $0.0115(83.7)$ & 0.5 & 7.8 & 85.1 & 6.6 \\
1994 & $0.00107(7.2)$ & $0.0138(92.8)$ & 1.1 & 8.1 & 86.3 & 4.5 \\
1995 & $0.00061(4.2)$ & $0.0141(95.8)$ & 0.5 & 7.7 & 87.0 & 4.8 \\
1996 & $0.00035(2.6)$ & $0.0131(97.4)$ & 1.6 & 7.1 & 86.5 & 4.8 \\
1997 & $0.00025(1.7)$ & $0.0144(98.3)$ & 1.4 & 7.9 & 85.5 & 5.2 \\
1998 & $0.00052(2.9)$ & $0.0170(97.1)$ & 4.1 & 10.6 & 80.7 & 4.6 \\
1999 & $0.00054(2.8)$ & $0.0189(97.2)$ & 6.2 & 13.6 & 76.3 & 4.0 \\
\hline
\end{tabular}


Table 4 Inter-group and intra-group inequalities in Japan

\begin{tabular}{|c|c|c|c|c|c|c|c|c|c|}
\hline \multirow[b]{2}{*}{ Year } & \multirow{2}{*}{$\begin{array}{l}\text { Inter-group } \\
\text { inequality (\%) }\end{array}$} & \multirow{2}{*}{$\begin{array}{l}\text { Intra-group } \\
\text { inequality (\%) }\end{array}$} & \multicolumn{7}{|c|}{ Shares $(\%)$ in intra-group inequality } \\
\hline & & & $\begin{array}{l}\text { Hokkaido } \\
\text { /Tohoku }\end{array}$ & Kanto & $\begin{array}{l}\text { Hokuriku } \\
\text { /Chubu }\end{array}$ & Kinki & Chugoku & Shikoku & $\begin{array}{l}\text { Kyushu } \\
\text { /Okinawa }\end{array}$ \\
\hline 1970 & $0.0120(37.9)$ & $0.0196(62.1)$ & 2.8 & 42.8 & 8.2 & 18.0 & 14.3 & 0.9 & 12.9 \\
\hline 1971 & $0.0099(36.4)$ & $0.0173(63.6)$ & 3.1 & 46.6 & 7.1 & 17.0 & 12.8 & 0.6 & 12.9 \\
\hline 1972 & $0.0084(34.4)$ & $0.0160(65.6)$ & 3.1 & 46.2 & 7.5 & 18.3 & 13.6 & 0.7 & 10.7 \\
\hline 1973 & $0.0065(29.6)$ & $0.0155(70.4)$ & 3.7 & 46.3 & 6.6 & 20.0 & 12.5 & 1.4 & 9.5 \\
\hline 1974 & $0.0046 \quad(24.5)$ & $0.0143(75.5)$ & 3.9 & 50.2 & 5.4 & 19.5 & 9.5 & 1.7 & 9.7 \\
\hline 1975 & $0.0039(24.5)$ & $0.0120(75.5)$ & 3.4 & 50.2 & 7.8 & 16.7 & 9.7 & 2.4 & 9.7 \\
\hline 1976 & $0.0044 \quad(27.1)$ & $0.0119(72.9)$ & 3.7 & 50.1 & 8.6 & 17.7 & 8.5 & 1.5 & 9.9 \\
\hline 1977 & 0.0034 & $0.0123(78.3)$ & 3.6 & 52.9 & 7.8 & 16.2 & 7.0 & 2.0 & 10.5 \\
\hline 1978 & $0.0034(22.0)$ & $0.0120(78.0)$ & 3.7 & 53.9 & 8.7 & 15.3 & 6.8 & 1.2 & 10.3 \\
\hline 1979 & $0.0037 \quad(23.3)$ & $0.0123(76.7)$ & 2.9 & 51.6 & 9.4 & 14.6 & 7.3 & 2.1 & 12.1 \\
\hline 1980 & $0.0040 \quad(24.1)$ & $0.0126 \quad(75.9)$ & 4.3 & 49.3 & 7.4 & 19.0 & 5.7 & 2.4 & 11.9 \\
\hline 1981 & $0.0046 \quad(26.8)$ & $0.0126 \quad(73.2)$ & 4.6 & 52.3 & 8.5 & 18.4 & 4.9 & 1.6 & 9.6 \\
\hline 1982 & $0.0047 \quad(26.2)$ & $0.0131 \quad(73.8)$ & 4.4 & 56.0 & 8.8 & 17.1 & 4.9 & 1.6 & 7.4 \\
\hline 1983 & $0.0053(28.4)$ & $0.0134 \quad(71.6)$ & 4.4 & 57.2 & 7.9 & 17.5 & 5.5 & 1.3 & 6.1 \\
\hline 1984 & $0.0057 \quad(31.1)$ & $0.0126(68.9)$ & 4.2 & 60.2 & 7.9 & 17.8 & 3.3 & 1.0 & 5.6 \\
\hline 1985 & $0.0067(34.9)$ & $0.0126(65.1)$ & 4.5 & 59.2 & 8.8 & 16.6 & 4.7 & 1.5 & 4.6 \\
\hline 1986 & $0.0065 \quad(31.7)$ & $0.0139(68.3)$ & 4.5 & 60.0 & 8.5 & 16.8 & 4.4 & 1.9 & 3.9 \\
\hline 1987 & 0.0070 & $0.0140(66.6)$ & 4.1 & 62.9 & 8.8 & 15.3 & 3.5 & 1.2 & 4.1 \\
\hline 1988 & $0.0080 \quad(34.6)$ & $0.0151 \quad(65.4)$ & 4.2 & 61.4 & 8.2 & 16.4 & 3.7 & 1.3 & 4.9 \\
\hline 1989 & 0.0078 & $0.0161 \quad(67.5)$ & 3.6 & 63.3 & 8.1 & 15.0 & 3.6 & 1.7 & 4.6 \\
\hline 1990 & $0.0082(33.4)$ & $0.0163 \quad(66.6)$ & 3.6 & 61.8 & 8.1 & 16.2 & 3.8 & 2.1 & 4.5 \\
\hline 1991 & $0.0078 \quad(32.6)$ & $0.0161 \quad(67.4)$ & 4.5 & 56.4 & 8.8 & 19.1 & 3.9 & 2.4 & 4.9 \\
\hline 1992 & $0.0061 \quad(28.6)$ & $0.0153(71.4)$ & 4.2 & 56.4 & 7.7 & 20.7 & 4.0 & 2.2 & 4.8 \\
\hline 1993 & $0.0052(26.7)$ & $0.0144 \quad(73.3)$ & 4.2 & 59.4 & 6.8 & 19.0 & 3.4 & 2.1 & 5.0 \\
\hline 1994 & $0.0046(25.6)$ & $0.0133 \quad(74.4)$ & 3.6 & 59.8 & 7.2 & 19.3 & 2.8 & 1.9 & 5.4 \\
\hline 1995 & 0.0045 & 0.0138 & 3.4 & 59.6 & 6.9 & 19.9 & 3.0 & 2.1 & 5.1 \\
\hline 1996 & $0.0046 \quad(25.2)$ & $0.0136(74.8)$ & 3.6 & 57.8 & 7.8 & 21.1 & 2.8 & 2.2 & 4.7 \\
\hline 1997 & $0.0044 \quad(24.2)$ & $0.0137(75.8)$ & 3.6 & 59.4 & 6.6 & 20.0 & 2.4 & 2.5 & 5.5 \\
\hline 1998 & $0.0037 \quad(22.2)$ & $0.0130 \quad(77.8)$ & 3.6 & 60.9 & 7.3 & 18.8 & 1.8 & 2.4 & 5.2 \\
\hline 1999 & $0.0037 \quad(22.9)$ & 0.0124 & 3.4 & 62.7 & 6.8 & 18.9 & 1.5 & 1.5 & 5.2 \\
\hline
\end{tabular}
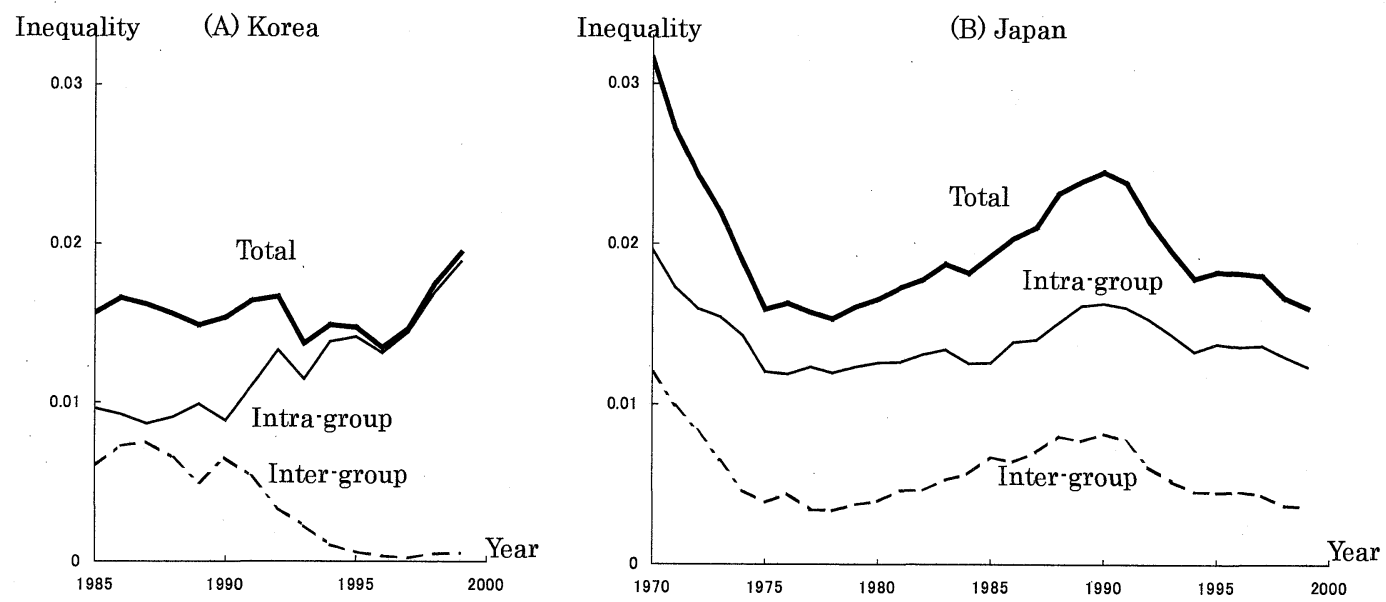

Fig. 2 Variations of inter-group and intra-group inequality for (A) Korea and (B) Japan given in Table 3 and 4 
each year, which continuously increased from 1970 to 1984 and subsequently hovers at around $60 \%$ of its total intra-group inequality, the Kinki has the 2 nd highest share. These show that the inequality among the Kanto and the Kinki prefectures is serious.

\subsection{Inequality variations by expanded rank-size functions ${ }^{9)}$}

Based on schemes of grouping and aggregation that have geographical or economic background to illustrate inequality variations between or within groups, Theil entropy measure cannot explain inequality variations of the individual region caused by flows of production factors. On the other hand, the expanded rank-size functions can be used to explore the regions among which high-level inequality occurs in a system, as well as inequality variations of an individual region (Fan and Casetti [6]).

Figure 3 illustrates the distribution of the logarithm of per capita GRDP as a function of the logarithm of the rank. Examining the case of Korea in Fig. 3A, the slopes tend to be steeper at the lower ranks (i.e. higher rank numbers), though it shows a nearly linear distribution generally. In Fig. 3B, for the case of Japan, the steeper slope for lower ranks is more obvious. Such a tendency is unexplainable according to Eq. (2) because Eq. (2) impliesthat these slopes estimated by $\beta$ should be linear. Hence, a simple expansion of rank-size function is presented below to overcome this problem.

\subsubsection{Expansions with respect to rank}

In order to explain changes in the slope with the rank, parameter $\beta$ in Eq. (2) is expanded with respect to rank. The slope coefficient $\beta$ may be defined as a linear function of rank $(r)$ or of the square of rank $\left(r^{2}\right)$ :

$$
\begin{aligned}
& \beta=\beta_{0}+\beta_{1} r \\
& \beta=\beta_{0}+\beta_{1} \gamma^{2}
\end{aligned}
$$
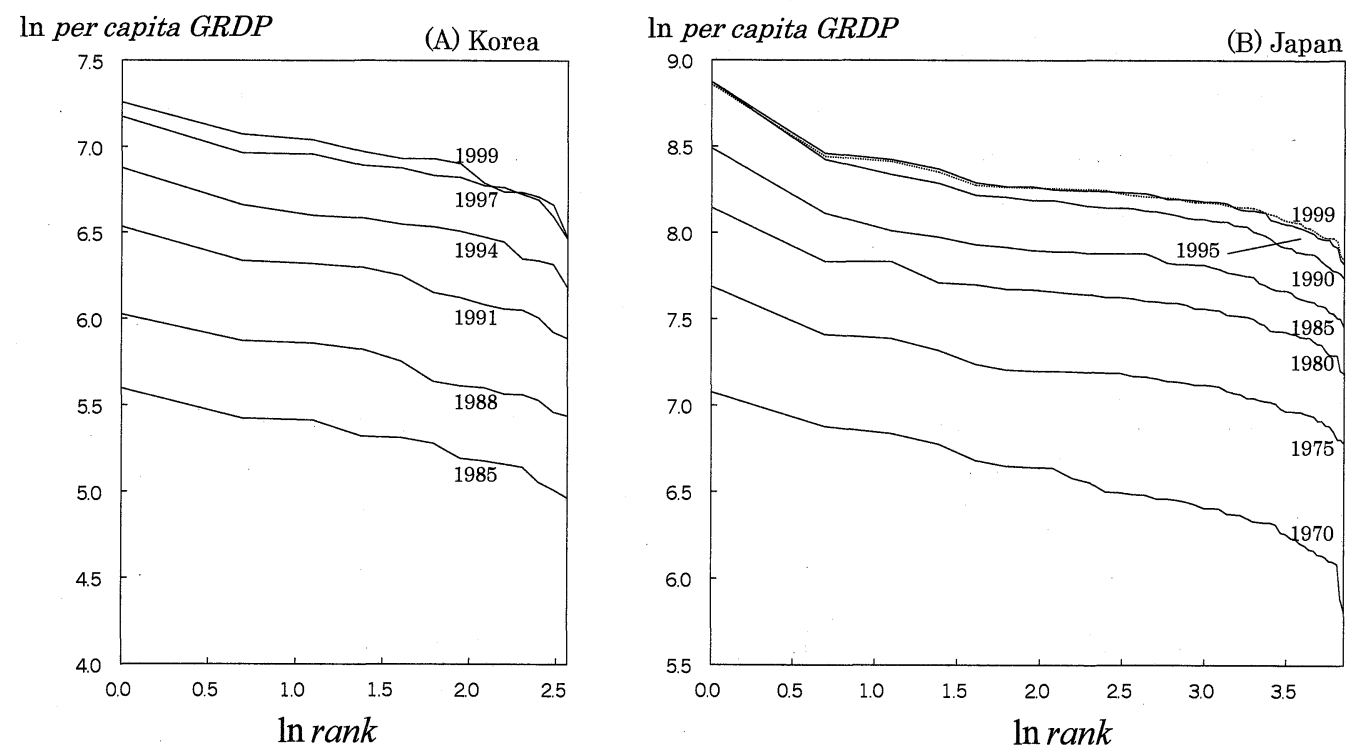

Fig. 3 Rank-size curves 
Here, expansion in Eq. (5) explains linear increases or decreases of inequality with rank, while Eq. (6) accounts for the more rapid variations of inequality with rank. Substituting each of these expansion equations into model (2), we can get two terminal models:

$$
\begin{aligned}
& \ln S_{y}=\alpha+\beta_{0} \ln r+\beta_{1} r \ln r \\
& \ln S_{y}=\alpha+\beta_{0} \ln r+\beta_{1} r^{2} \ln r
\end{aligned}
$$

Selection of the more suitable model in Eq. (7) and (8) is based on coefficients of determination $\left(R^{2}\right)$ by regression analysis applied to the available data.

\subsubsection{Expansions with respect to rank and time}

Anther important aspect of inequality variations involves changes in inequality over time. Based on Eq. (7) and (8), it is possible to interpret dynamic variations of interregional inequality.

The coefficient $\alpha$ in Eq. (7) and (8) represents the intercept of the rank-size curve, which is used to evaluate the level of the highest region $(r=1)$. If $\alpha$ is defined as a function of time, it explains change of income level in the richest regions over time. However, since variations in inequality are to be investigated here rather than changes of income, by changing the income of individual regions into an index, it is possible to reduce the complexities in expansion of Eq. (7) and (8) with respect to time:

$$
S_{y}^{\prime}=q\left(S_{y i} / S_{y a}\right)
$$

where $S_{y i}$ is the income of the $i^{\text {th }}$ region, $S_{y a}$ is the income of the richest region $(r=1)$, and $q$ is a constant, which is arbitrarily assigned a value of 100 . By substituting $S_{y}^{\prime}$ for $S_{y}$ in Eq. (7) and (8), the temporal expansion of $\alpha$ becomes unnecessary since $S_{y}^{\prime}$ for the richest region always equals $q$ which does not change over time.

Next, the time-dependent parameters $\beta_{0}$ and $\beta_{1}$ in Eq. (7) and (8) can be expanded as:

$$
\begin{aligned}
& \beta_{0}=\beta_{00}+\beta_{01} t+\cdots+\beta_{0 m} t^{m} \\
& \beta_{1}=\beta_{10}+\beta_{11} t+\cdots+\beta_{1 n} t^{n}
\end{aligned}
$$

Here, the appropriate expansion with respect to time is determined by the hypothesis testing approach. ${ }^{10)}$ Substituting these newly derived Eq. (10), (11) and (9) into Eq. (7) and (8) yields the final terminal models :

$$
\begin{aligned}
& \ln S_{y}^{\prime}=\alpha+\beta_{00} \ln r+\beta_{01} t \ln r+\cdots+\beta_{0 m} t^{m} \ln r+\beta_{10} r \ln r+\beta_{11} t r \ln r+\cdots+\beta_{1 n} t^{n} r \ln r \\
& \ln S_{y}^{\prime}=\alpha+\beta_{00} \ln r+\beta_{01} t \ln r+\cdots+\beta_{0 m} t^{m} \ln r+\beta_{10} r^{2} \ln r+\beta_{11} t r^{2} \ln r+\cdots+\beta_{1 n} t^{n} r^{2} \ln r
\end{aligned}
$$

The individual parameters can be evaluated in Eq. (12) and (13), and once Eq. (10) and (11) are substituted into (5) and (6), inequality measure $\beta$ can be reconstructed as

$$
\begin{aligned}
& \beta=\beta_{00}+\beta_{01} t+\cdots+\beta_{0 m} t^{m}+\beta_{10} r+\beta_{11} t r+\cdots+\beta_{1 n} t^{n} r \\
& \beta=\beta_{00}+\beta_{01} t+\cdots+\beta_{0 m} t^{m}+\beta_{10} r^{2}+\beta_{11} t r^{2}+\cdots+\beta_{1 n} t^{n} r^{2}
\end{aligned}
$$

The above approaches are applied to Korea and Japan, respectively. 


\subsection{Inequality variations in Korea}

First, let us expand parameter $\beta$ in Eq. (2) with respect to rank. Table 5 presents the estimated values for models (7) and (8), expanded with respect to rank. The coefficients of determination $\left(R^{2}\right)$ are significant improvements over the moderate $R^{2}$ 's associated with the unexpanded rank-size function reported in Table 1 . The estimates for $\beta_{0}$ and $\beta_{1}$ are negative and generally significant for both models, which indicates that as $r$ increases, inequality between regions tends to become greater, that is, the inequality in between the high (low) income regions is low (high).

Next, parameters $\beta_{0}$ and $\beta_{1}$ in models (7) and (8) are expanded with respect to time. Since the $R^{2}$ 's associated with model (8) are generally higher than those for model (7) (see Table 5), in the following, only the results from expansions based on model (8) are shown. Temporal expansions require creating a new discrete variable $t$, which is assigned the following values: $t=0$ for $1985, t=1$ for $1986, \cdots, t=14$ for 1999 . In the expansion of the coefficient $\alpha$ with respect to time, the complexity can be reduced by conversion as shown in Eq. (9). The expansion equations for parameters $\beta_{0}$ and $\beta_{1}$ are determined by a hypothesistesting approach, and the results suggest the selection of the $3 \mathrm{rd}$ and the $4^{\text {th }}$ order temporal expansion respectively. ${ }^{11)}$ Therefore the expansion equations are:

$$
\begin{aligned}
& \beta_{0}=\beta_{00}+\beta_{01} t+\beta_{02} t^{2}+\beta_{03} t^{3} \\
& \beta_{1}=\beta_{10}+\beta_{11} t+\beta_{12} t^{2}+\beta_{13} t^{3}+\beta_{14} t^{4}
\end{aligned}
$$

Using the index $S_{y}^{\prime}$ to replace $S_{y}$, and then substituting the RHS of (16) and (17) into model (8) yields the final terminal model:

$$
\begin{aligned}
\ln S_{y}^{\prime}= & \alpha+\beta_{00} \ln r+\beta_{01} t \ln r+\beta_{02} t^{2} \ln r+\beta_{03} t^{3} \ln r \\
& +\beta_{10} r^{2} \ln r+\beta_{11} t r^{2} \ln r+\beta_{12} t^{2} r^{2} \ln r+\beta_{13} t^{3} r^{2} \ln r+\beta_{14} t^{4} r^{2} \ln r
\end{aligned}
$$

Table 5 Estimates for rank-size function expanded with respect to rank in Korea

\begin{tabular}{c|ccc|cccc}
\hline \multirow{2}{*}{ Year } & \multicolumn{3}{|c|}{ Estimates of $\beta$ for model (7) } & \multicolumn{3}{c}{ Estimates of $\beta$ for model (8) } \\
\cline { 2 - 8 } & \multicolumn{2}{|c}{$\beta_{0}$} & \multicolumn{2}{c}{$\beta_{1}$} & $R^{2}$ & $\beta_{0}$ & \multicolumn{2}{c}{$\beta_{1}$} & $R^{2}$ \\
\hline 1985 & $-0.129(5.04)^{* *}$ & $-0.0076(4.33)^{* *}$ & 0.98 & $-0.160(10.01)^{* *}$ & $-0.00045(5.30)^{* *}$ & 0.98 \\
1986 & $-0.156(5.06)^{* *}$ & $-0.0060(2.81)^{*}$ & 0.97 & $-0.183(8.38)^{* *}$ & $-0.00034(2.94)^{*}$ & 0.97 \\
1987 & $-0.162(5.66)^{* *}$ & $-0.0053(2.70)^{*}$ & 0.97 & $-0.189(8.87)^{* *}$ & $-0.00028(2.50)^{*}$ & 0.97 \\
1988 & $-0.156(5.67)^{* *}$ & $-0.0055(2.90)^{*}$ & 0.97 & $-0.184(8.92)^{* *}$ & $-0.00029(2.65)^{*}$ & 0.97 \\
1989 & $-0.132(4.52)^{* *}$ & $-0.0070(3.47)^{* *}$ & 0.97 & $-0.163(7.91)^{* *}$ & $-0.00039(3.57)^{* *}$ & 0.97 \\
1990 & $-0.133(5.15)^{* *}$ & $-0.0071(4.01)^{* *}$ & 0.97 & $-0.167(8.82)^{* *}$ & $-0.00039(3.89)^{* *}$ & 0.97 \\
1991 & $-0.140(5.10)^{* *}$ & $-0.0071(3.77)^{* *}$ & 0.97 & $-0.171(9.20)^{* *}$ & $-0.00041(4.19)^{* *}$ & 0.98 \\
1992 & $-0.142(3.66)^{* *}$ & $-0.0068(2.54)^{*}$ & 0.94 & $-0.167(6.52)^{* *}$ & $-0.00042(3.10)^{*}$ & 0.95 \\
1993 & $-0.090(2.23)$ & $-0.0091(3.29)^{* *}$ & 0.93 & $-0.126(4.80)^{* *}$ & $-0.00054(3.93)^{* *}$ & 0.94 \\
1994 & $-0.123(2.92)^{*}$ & $-0.0073(2.49)^{*}$ & 0.93 & $-0.146(5.51)^{* *}$ & $-0.00047(3.39)^{* *}$ & 0.95 \\
1995 & $-0.130(2.91)^{*}$ & $-0.0065(2.11)$ & 0.92 & $-0.148(5.24)^{* *}$ & $-0.00045(2.99)^{*}$ & 0.94 \\
1996 & $-0.114(2.47)^{*}$ & $-0.0070(2.20)$ & 0.91 & $-0.135(4.57)^{* *}$ & $-0.00047(2.99)^{*}$ & 0.93 \\
1997 & $-0.099(2.16)$ & $-0.0089(2.82)^{*}$ & 0.92 & $-0.128(4.59)^{* *}$ & $-0.00058(3.90)^{* *}$ & 0.94 \\
1998 & $-0.116(2.28)^{*}$ & $-0.0092(2.64)^{*}$ & 0.91 & $-0.147(4.56)^{* *}$ & $-0.00059(3.44)^{* *}$ & 0.93 \\
1999 & $-0.110(2.51)^{*}$ & $-0.0109(3.62)^{* *}$ & 0.94 & $-0.152(5.53)^{* *}$ & $-0.00065(4.48)^{* *}$ & 0.96 \\
\hline
\end{tabular}

Note: ${ }^{*}, *$ significant at the $5 \%$ and $1 \%$ level respectively. $t$-values are in parentheses. 
Then, inequality measure $\beta$ can be reconstructed by using expansion Eq. (6) in conjunction with expansion Eq. (16) and (17) :

$$
\beta=\beta_{00}+\beta_{01} t+\beta_{02} t^{2}+\beta_{03} t^{3}+\beta_{10} r^{2}+\beta_{11} t r^{2}+\beta_{12} t^{2} r^{2}+\beta_{13} t^{3} r^{2}+\beta_{14} t^{4} r^{2}
$$

Table 6 reports regression estimates for model Eq. (18), from which the estimates for Eq. (19) are as follows:

$$
\begin{aligned}
\beta= & -0.159+0.0022 t-(4.83 \mathrm{E}-4) t^{2}+(2.56 \mathrm{E}-5) t^{3}-(4.55 \mathrm{E}-4) r^{2}+(7.71 \mathrm{E}-5) t r^{2} \\
& -(2.74 \mathrm{E}-5) t^{2} r^{2}+(3.3 \mathrm{E}-6) t^{3} r^{2}-(1.29 \mathrm{E}-7) t^{4} r^{2}
\end{aligned}
$$

Figures 4, 5 and 6 illustrate the inequality measure $-\beta$, which is estimated from Eq. (20). In short, high values represent high-level inequality, and low values low-level inequality. Figures $4 \mathrm{~A}$ and $4 \mathrm{~B}$ are depicted by substituting arbitrarily selected values for $t$, while Fig. 5 has arbitrarily selected $r$.

Figure 4 shows that in all cases inter-regional inequality for Korea is lower at high ranks and becomes higher toward lower ranks. The general positions of the curves indicate that inequality throughout the ranks has declined between 1985 and1987 (Fig. 4A) and has increased between 1987 and 1999 (Fig. 4B). Conspicuously, changes in position are also

Table 6 Estimates for rank-size function expanded with respect to rank and time in Korea

\begin{tabular}{rcrc}
\hline Variable & Parameter & Estimate & \multicolumn{1}{c}{$t$-value } \\
\hline Constant & $\alpha$ & 4.5709 & $544.70^{* *}$ \\
$\ln \mathrm{r}$ & $\beta_{00}$ & -0.1591 & $-13.78^{* *}$ \\
$\mathrm{t} \ln \mathrm{r}$ & $\beta_{01}$ & 0.0022 & 0.34 \\
$\mathrm{t}^{2} \ln \mathrm{r}$ & $\beta_{02}$ & $-4.83 \mathrm{E}-4$ & -0.44 \\
$\mathrm{t}^{3} \ln \mathrm{r}$ & $\beta_{03}$ & $2.56 \mathrm{E}-5$ & 0.50 \\
$\mathrm{r}^{2} \ln \mathrm{r}$ & $\beta_{10}$ & $-4.55 \mathrm{E}-4$ & $-4.62^{* *}$ \\
$\mathrm{t} \mathrm{r}^{2} \ln \mathrm{r}$ & $\beta_{11}$ & $7.71 \mathrm{E}-5$ & 1.03 \\
$\mathrm{t}^{2} \mathrm{r}^{2} \ln \mathrm{r}$ & $\beta_{12}$ & $-2.74 \mathrm{E}-5$ & -1.48 \\
$\mathrm{t}^{3} \mathrm{r}^{2} \ln \mathrm{r}$ & $\beta_{13}$ & $3.30 \mathrm{E}-6$ & 1.81 \\
$\mathrm{t}^{4} \mathrm{r}^{2} \ln \mathrm{r}$ & $\beta_{14}$ & $-1.29 \mathrm{E}-7$ & $-2.06^{*}$ \\
\hline & & $\bar{R}^{2}=0.949, F=409.84^{* *}$
\end{tabular}

Note: ${ }^{*, * *}$ significant at the $5 \%$ and $1 \%$ level respectively.
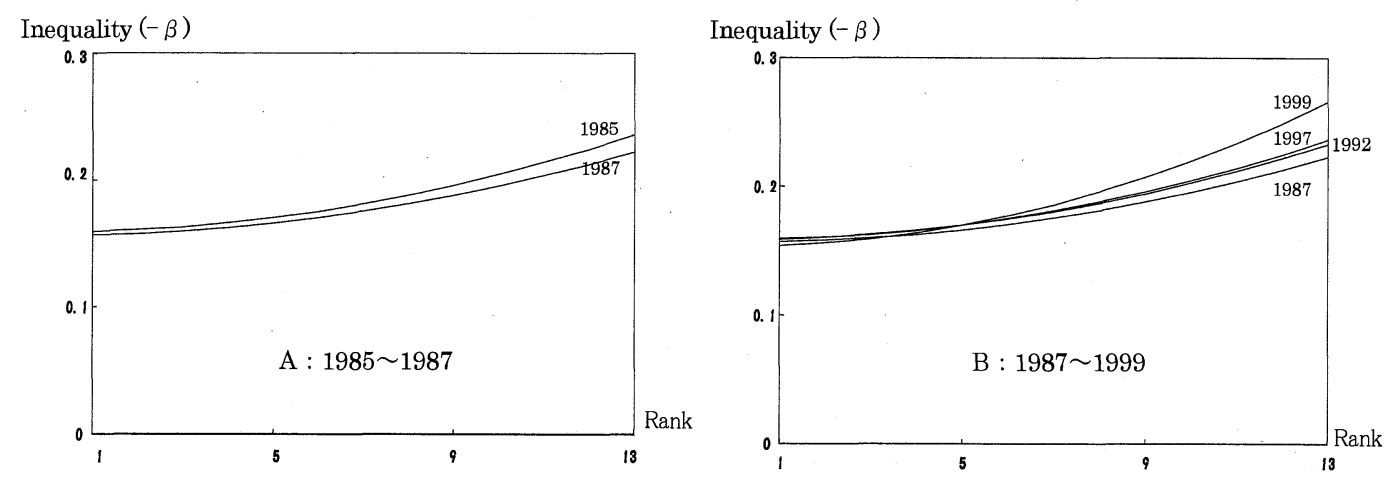

Fig. 4 Changes of inequality with respect to rank in Korea 


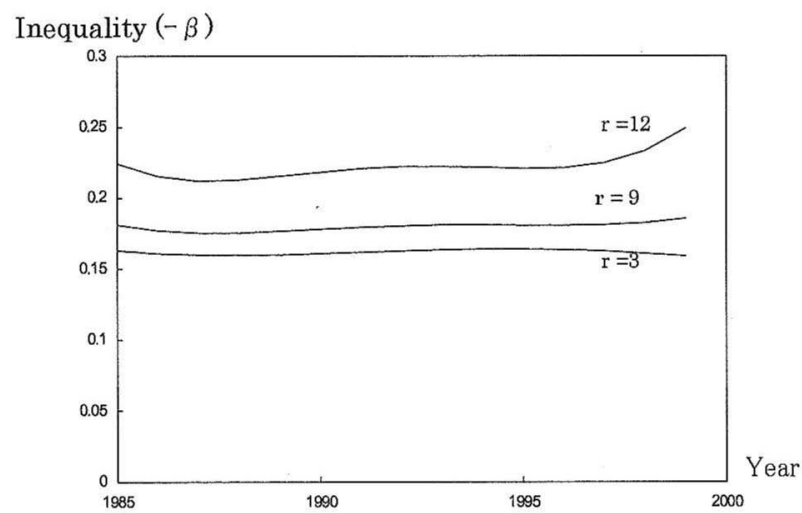

Fig. 5 Changes of inequality with respect to time in Korea
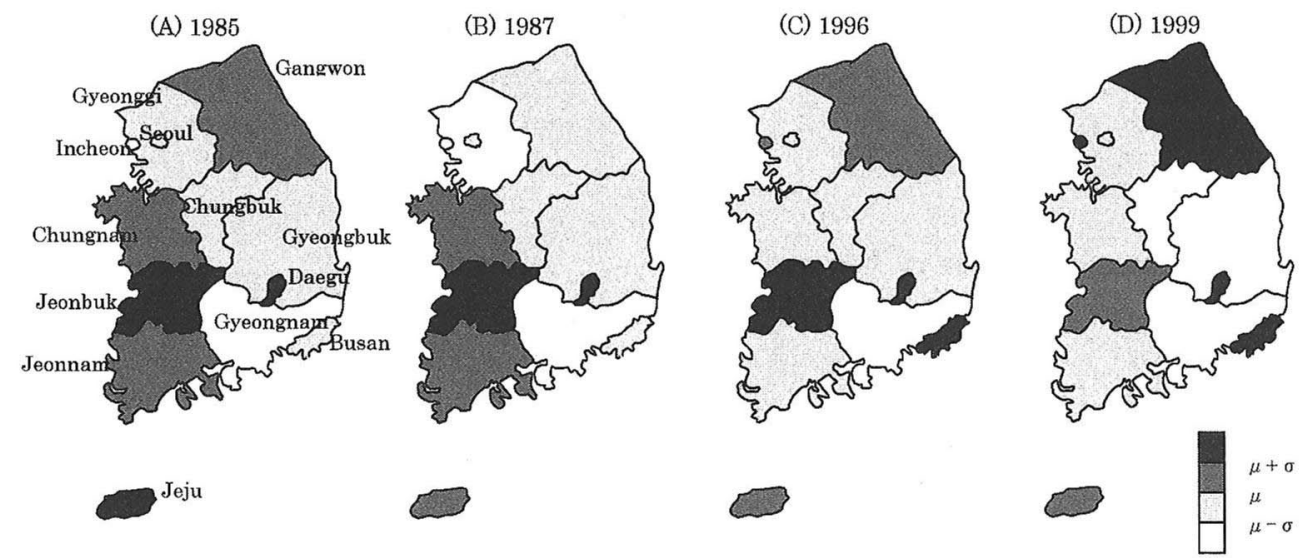

Fig. 6 Spatial variations of inequality in Korea

Note: $\mu$ is average pooled estimates of $-\beta$ from all years; $\sigma$ is standard deviation pooled estimates of $-\beta$ from all years.

accompanied by changes in slope. In particular, from 1997 to 1999, the inequality at low ranks has increased at a greater rate.

Figure 5 shows the temporal change of inequality in Korea for selected ranks. At $r=$ 12 (low rank), the change of inequality has decreased from 1985 to 1987, and then has increased sharply after 1990. However, characteristic change is not shown when rank $r$ is set at 3 or 9 , which shows that the change of inequality in Korea mainly has close relation to changes of low ranks that are low-income regions.

Figure 6 portrays changes of the inequality in individual regions of Korea, by plotting the estimated $-\beta$ for every region according to their rank at selected points in time. Shading classes are determined by dividing the region into four parts on the basis of an average ( $\mu=$ $0.186)$ and standard deviation $(\sigma=0.025)$ pooled estimates from all years. For the sake of simplicity, these four classes are referred to as high inequality $(-\beta>\mu+\sigma)$, high/moderate inequality $(\mu+\sigma>-\beta>\mu)$, moderate/low inequality $(\mu>-\beta>\mu-\sigma)$ and low inequality $(\mu-\sigma>-\beta)$. The maps for 1985, 1987, 1996 and 1999 are selected for discussion. 
Figure 6 should be interpreted by focusing on both changes of the inequality of individual regions, and the spatial flows of production factors. The maps from 1985 to 1996 show spatial variations in the process of polarization reversal. Figure 6A indicates that in 1985 Capital metropolitan and Southeast, which are the traditional cores, were in low and moderate/low inequality categories, and that Central and Southwest generally were in high and high/moderate inequality categories. The map for 1987 (Fig. 6B) shows the increase in income of the peripheral regions, including Jeju and Gangwon.

Figure 6C indicates the shifts to the lower inequality categories in Chungnam and Jeonnam. These regions have emerged as new growth regions. In addition, the shifts to the higher inequality categories in Incheon and Busan are conspicuous.

Figure $6 \mathrm{D}$ depicts the spatial variations in spatial restructuring, which means that a regional inequality re-increases. Chungbuk and Gyeongbuk, which are high-income regions, shifted from moderate/low inequality into low inequality category. Then, Gangwon and Incheon shifted from high/moderate inequality into high inequality category. Interestingly, Jeonbuk in low-income regions shifted from high inequality into high/moderate inequality category. A comparison of 1999 with 1985 suggests new growth in the west coast area and sustained growth in the Southeast.

\subsection{Inequality variations in Japan}

The rank-size functions for Japan are also expanded as in the case of Korea. First, Eq. (2) is expanded with respect to rank. Table 7 reports the estimates for models (7) and (8). The coefficients of determination are significant improvements over the moderate $R^{2}$ 's associated with the unexpanded rank-size function reported in Table 2. The estimates for $\beta_{0}$ and $\beta_{1}$ are negative and generally significant for both models, which means that inequality between regions tends to become greater as $r$ increases.

Next, parameters $\beta_{0}$ and $\beta_{1}$ in models (7) and (8) are expanded with respect to time. As the $R^{2}$ 's associated with model (8) are generally higher than those with model (7) (see Table 7), in the following, only the results from expansions based on model (8) are reported. A new discrete variable $t$ is assigned the following values : $t=0$ for $1970, t=1$ for $1971, \cdots$, $t=29$ for 1999 .

In order to reduce complexity, the coefficient $\alpha$ is changed as shown in Eq. (9). Then, the expansion equations for parameters $\beta_{0}$ and $\beta_{1}$ are determined by a hypothesis-testing approach, and the results suggest the selection of a $5^{\text {th }}$ order temporal expansions for both. ${ }^{12)}$ Therefore the expansion equations are :

$$
\begin{aligned}
& \beta_{0}=\beta_{00}+\beta_{01} t+\beta_{02} t^{2}+\beta_{03} t^{3}+\beta_{04} t^{4}+\beta_{05} t^{5} \\
& \beta_{1}=\beta_{10}+\beta_{11} t+\beta_{12} t^{2}+\beta_{13} t^{3}+\beta_{14} t^{4}+\beta_{15} t^{5}
\end{aligned}
$$

Using the index $S_{y}^{\prime}$ to replace $S_{y}$, and substituting the RHS of (21) and (22) into model (8) yields the final terminal model:

$$
\begin{aligned}
\ln S_{y}^{\prime}= & \alpha+\beta_{00} \ln r+\beta_{01} t \ln r+\beta_{02} t^{2} \ln r+\beta_{03} t^{3} \ln r+\beta_{04} t^{4} \ln r+\beta_{05} t^{5} \ln r \\
& +\beta_{10} r^{2} \ln r+\beta_{11} t r^{2} \ln r+\beta_{12} t^{2} r^{2} \ln r+\beta_{13} t^{3} r^{2} \ln r+\beta_{14} t^{4} r^{2} \ln r+\beta_{15} t^{5} r^{2} \ln r
\end{aligned}
$$


Table 7 Estimates for rank-size function expanded with respect to rank in Japan

\begin{tabular}{|c|c|c|c|c|c|c|c|c|c|c|}
\hline \multirow{2}{*}{ Year } & \multicolumn{5}{|c|}{ Estimates of $\beta$ for model (7) } & \multicolumn{5}{|c|}{ Estimates of $\beta$ for model (8) } \\
\hline & & $\beta_{0}$ & $\beta$ & $\beta_{1}$ & $R^{2}$ & & $\beta_{0}$ & $\beta_{1}$ & & $R^{2}$ \\
\hline 1970 & -0.153 & $(8.27)^{* *}$ & -0.0020 & $(6.83)^{* *}$ & 0.95 & -0.181 & $(15.42)^{* *}$ & -0.000037 & $(9.18)^{* *}$ & 0.97 \\
\hline 1971 & -0.151 & $(8.79)^{* *}$ & -0.0017 & $(6.28) * *$ & 0.95 & -0.173 & $(15.82)^{* *}$ & -0.000032 & $(8.48)^{* *}$ & 0.97 \\
\hline 1972 & -0.161 & $(12.14)^{* *}$ & -0.0013 & $(6.10)^{* *}$ & 0.97 & -0.177 & $(21.20)^{* *}$ & -0.000024 & $(8.50)^{* *}$ & 0.98 \\
\hline 1973 & -0.159 & $(12.93)^{* *}$ & -0.0011 & $(5.61)^{* *}$ & 0.97 & -0.171 & $(22.23)^{* *}$ & -0.000021 & $(8.05)^{* *}$ & 0.98 \\
\hline 1974 & -0.143 & $(10.40)^{* *}$ & -0.0011 & $(4.85)^{* *}$ & 0.96 & -0.155 & $(17.20)^{* *}$ & -0.000021 & $(6.77)^{* *}$ & 0.97 \\
\hline 1975 & -0.127 & $(8.79)^{* *}$ & -0.0011 & $(4.59)^{* *}$ & 0.94 & -0.137 & $(14.55)^{* *}$ & -0.000021 & $(6.47)^{* *}$ & 0.96 \\
\hline 1976 & -0.128 & $(9.14)^{* *}$ & -0.0011 & $(4.91)^{* *}$ & 0.95 & -0.140 & $(15.38)^{* *}$ & -0.000021 & $(6.91)^{* *}$ & 0.96 \\
\hline 1977 & -0.130 & $(8.40)^{* *}$ & -0.0009 & $(3.82)^{* *}$ & 0.93 & -0.138 & $(13.30)^{* *}$ & -0.000019 & $(5.48)^{* *}$ & 0.95 \\
\hline 1978 & -0.133 & $(9.20) * *$ & -0.0009 & $(3.73)^{* *}$ & 0.94 & -0.140 & $(14.39)^{* *}$ & -0.000018 & $(5.39)^{* *}$ & 0.95 \\
\hline 1979 & -0.130 & $(9.79)^{* *}$ & -0.0010 & $(4.81)^{* *}$ & 0.95 & -0.142 & $(16.14)^{* *}$ & -0.000020 & $(6.61)^{* *}$ & 0.96 \\
\hline 1980 & -0.118 & $(7.56)^{* *}$ & -0.0012 & $(5.00)^{* *}$ & 0.94 & -0.132 & $(12.98)^{* *}$ & -0.000024 & $(6.96)^{* *}$ & 0.95 \\
\hline 1981 & -0.129 & $(7.61)^{* *}$ & -0.0011 & $(4.05)^{* *}$ & 0.93 & -0.139 & $(12.27)^{* *}$ & -0.000022 & $(5.70)^{* *}$ & 0.94 \\
\hline 1982 & -0.140 & $(8.29)^{* *}$ & -0.0009 & $(3.40)^{* *}$ & 0.93 & -0.147 & $(12.78)^{* *}$ & -0.000019 & $(4.93)^{* *}$ & 0.94 \\
\hline 1983 & -0.143 & $(8.48)^{* *}$ & -0.0010 & $(3.55)^{* *}$ & 0.93 & -0.151 & $(13.14)^{* *}$ & -0.000020 & $(5.02)^{* *}$ & 0.94 \\
\hline 1984 & -0.141 & $(8.03)^{* *}$ & -0.0009 & $(3.26)^{* *}$ & 0.92 & -0.148 & $(12.26)^{* *}$ & -0.000019 & $(4.71)^{* *}$ & 0.94 \\
\hline 1985 & -0.141 & $(7.86)^{* *}$ & -0.0010 & $(3.51)^{* *}$ & 0.92 & -0.150 & $(12.17)^{* *}$ & -0.000020 & $(4.88)^{* *}$ & 0.94 \\
\hline 1986 & -0.153 & $(8.21)^{* *}$ & -0.0009 & $(2.89) * *$ & 0.92 & -0.158 & $(12.22)^{* *}$ & -0.000018 & $(4.18)^{* *}$ & 0.93 \\
\hline 1987 & -0.160 & $(8.25)^{* *}$ & -0.0008 & $(2.45)^{*}$ & 0.92 & -0.163 & $(11.95)^{* *}$ & -0.000017 & $(3.65)^{* *}$ & 0.93 \\
\hline 1988 & -0.164 & $(8.46)^{* *}$ & -0.0009 & $(2.80)^{* *}$ & 0.92 & -0.169 & $(12.53)^{* *}$ & -0.000019 & $(4.11)^{* *}$ & 0.93 \\
\hline 1989 & -0.174 & $(8.37)^{* *}$ & -0.0007 & $(2.10)^{*}$ & 0.91 & -0.175 & $(11.89)^{* *}$ & -0.000016 & $(3.30)^{* *}$ & 0.92 \\
\hline 1990 & -0.175 & $(8.68)^{* *}$ & -0.0007 & $(2.34)^{*}$ & 0.92 & -0.177 & $(12.49) * *$ & -0.000017 & $(3.58)^{* *}$ & 0.93 \\
\hline 1991 & -0.165 & $(8.52)^{* *}$ & -0.0009 & $(3.03)^{* *}$ & 0.93 & -0.171 & $(12.81)^{* *}$ & -0.000020 & $(4.45)^{* *}$ & 0.94 \\
\hline 1992 & -0.160 & $(8.08)^{* *}$ & -0.0008 & $(2.56)^{*}$ & 0.91 & -0.163 & $(11.83)^{* *}$ & -0.000018 & $(3.92)^{* *}$ & 0.93 \\
\hline 1993 & -0.154 & $(7.73)^{* *}$ & -0.0007 & $(2.29)^{*}$ & 0.90 & -0.156 & $(11.12)^{* *}$ & -0.000017 & $(3.58)^{* *}$ & 0.92 \\
\hline 1994 & -0.148 & $(7.50)^{* *}$ & -0.0007 & $(2.16)^{*}$ & 0.90 & -0.148 & $(10.70)^{* *}$ & -0.000016 & $(3.48)^{* *}$ & 0.91 \\
\hline 1995 & -0.145 & $(7.24)^{* *}$ & -0.0008 & $(2.43)^{*}$ & 0.90 & -0.147 & $(10.53)^{* *}$ & -0.000018 & $(3.81)^{* *}$ & 0.91 \\
\hline 1996 & -0.147 & $(7.83)^{* *}$ & -0.0008 & $(2.60)^{*}$ & 0.91 & -0.149 & $(11.53)^{* *}$ & -0.000018 & $(4.10)^{* *}$ & 0.93 \\
\hline 1997 & -0.143 & $(7.16)^{* *}$ & -0.0008 & $(2.51)^{*}$ & 0.90 & -0.145 & $(10.47)^{* *}$ & -0.000018 & $(3.91)^{* *}$ & 0.91 \\
\hline 1998 & -0.144 & $(7.24)^{* *}$ & -0.0006 & $(2.01)$ & 0.89 & -0.143 & $(10.23)^{* *}$ & -0.000016 & $(3.35)^{* *}$ & 0.90 \\
\hline 1999 & -0.143 & $(7.18)^{* *}$ & -0.0006 & $(1.77)$ & 0.88 & -0.141 & $(9.96) * *$ & -0.000015 & $(3.07)^{* *}$ & 0.90 \\
\hline
\end{tabular}

Note: ${ }^{*, * *}$ significant at the $5 \%$ and $1 \%$ level respectively. $t$-values are in parentheses.

Then, inequality measure $\beta$ can be reconstructed using expansion Eq. (6) in conjunction with expansion Eq. (21) and (22) :

$$
\beta=\beta_{00}+\beta_{01} t+\beta_{02} t^{2}+\beta_{03} t^{3}+\beta_{04} t^{4}+\beta_{05} t^{5}+\beta_{10} r^{2}+\beta_{11} t r^{2}+\beta_{12} t^{2} \gamma^{2}+\beta_{13} t^{3} r^{2}+\beta_{14} t^{4} r^{2}+\beta_{15} t^{5} r^{2}
$$

Table 8 reports regression estimates for model (23), from which the estimates for (24) are as follows:

$$
\begin{aligned}
\beta= & -0.127-0.0011 t-0.0042 t^{2}-0.0005 t^{3}+(2.16 \mathrm{E}-5) t^{4}-(3.08 \mathrm{E}-7) t^{5}-(4.8 \mathrm{E}-5) r^{2} \\
& +(1.1 \mathrm{E}-5) t r^{2}-(1.91 \mathrm{E}-6) t^{2} r^{2}+(1.55 \mathrm{E}-7) t^{3} r^{2}-(5.63 \mathrm{E}-9) t^{4} r^{2}+(7.39 \mathrm{E}-11) t^{5} r^{2}
\end{aligned}
$$

Figures 7, 8 and 9 portray variations of inequality $-\beta$, based upon Eq. (25). Figures 7A, 7B and $7 \mathrm{C}$ are depicted by substituting arbitrarily selected values for $t$, while Fig. 8 uses 
Table 8 Estimates for rank-size function expanded with respect to rank and time in Japan

\begin{tabular}{rcrr}
\hline Variable & Parameter & Estimate & t-value \\
\hline Constant & $\alpha$ & 4.4026 & $798.18^{* *}$ \\
$\ln \mathrm{r}$ & $\beta_{00}$ & -0.1274 & $29.58^{* *}$ \\
$\mathrm{t} \ln \mathrm{r}$ & $\beta_{01}$ & -0.0106 & $-3.38^{* *}$ \\
$\mathrm{t}^{2} \ln \mathrm{r}$ & $\beta_{02}$ & 0.0042 & $-6.93^{* *}$ \\
$\mathrm{t}^{3} \ln \mathrm{r}$ & $\beta_{03}$ & -0.0005 & $9.23^{* *}$ \\
$\mathrm{t}^{4} \ln \mathrm{r}$ & $\beta_{04}$ & $2.16 \mathrm{E}-5$ & $-10.38^{* *}$ \\
$\mathrm{t}^{5} \ln \mathrm{r}$ & $\beta_{05}$ & $-3.08 \mathrm{E}-7$ & $10.80^{* *}$ \\
$\mathrm{r}^{2} \ln \mathrm{r}$ & $\beta_{10}$ & $-4.81 \mathrm{E}-5$ & $-15.73^{* *}$ \\
$\mathrm{t} \mathrm{r}^{2} \ln \mathrm{r}$ & $\beta_{11}$ & $1.10 \mathrm{E}-5$ & $-4.92^{* *}$ \\
$\mathrm{t}^{2} \mathrm{r}^{2} \ln \mathrm{r}$ & $\beta_{12}$ & $-1.91 \mathrm{E}-6$ & $3.93^{* *}$ \\
$\mathrm{t}^{3} \mathrm{r}^{2} \ln \mathrm{r}$ & $\beta_{13}$ & $1.55 \mathrm{E}-7$ & $-3.50^{* *}$ \\
$\mathrm{t}^{4} \mathrm{r}^{2} \ln \mathrm{r}$ & $\beta_{14}$ & $-5.63 \mathrm{E}-9$ & $3.32^{* *}$ \\
$\mathrm{t}^{5} \mathrm{r}^{2} \ln \mathrm{r}$ & $\beta_{15}$ & $7.39 \mathrm{E}-11$ & $-3.17^{* *}$ \\
\hline & \multicolumn{4}{c}{$\bar{R}^{2}=0.936, F=1728.90^{* *}$} \\
Note : ${ }^{* *}$ significant at the 1\% level.
\end{tabular}

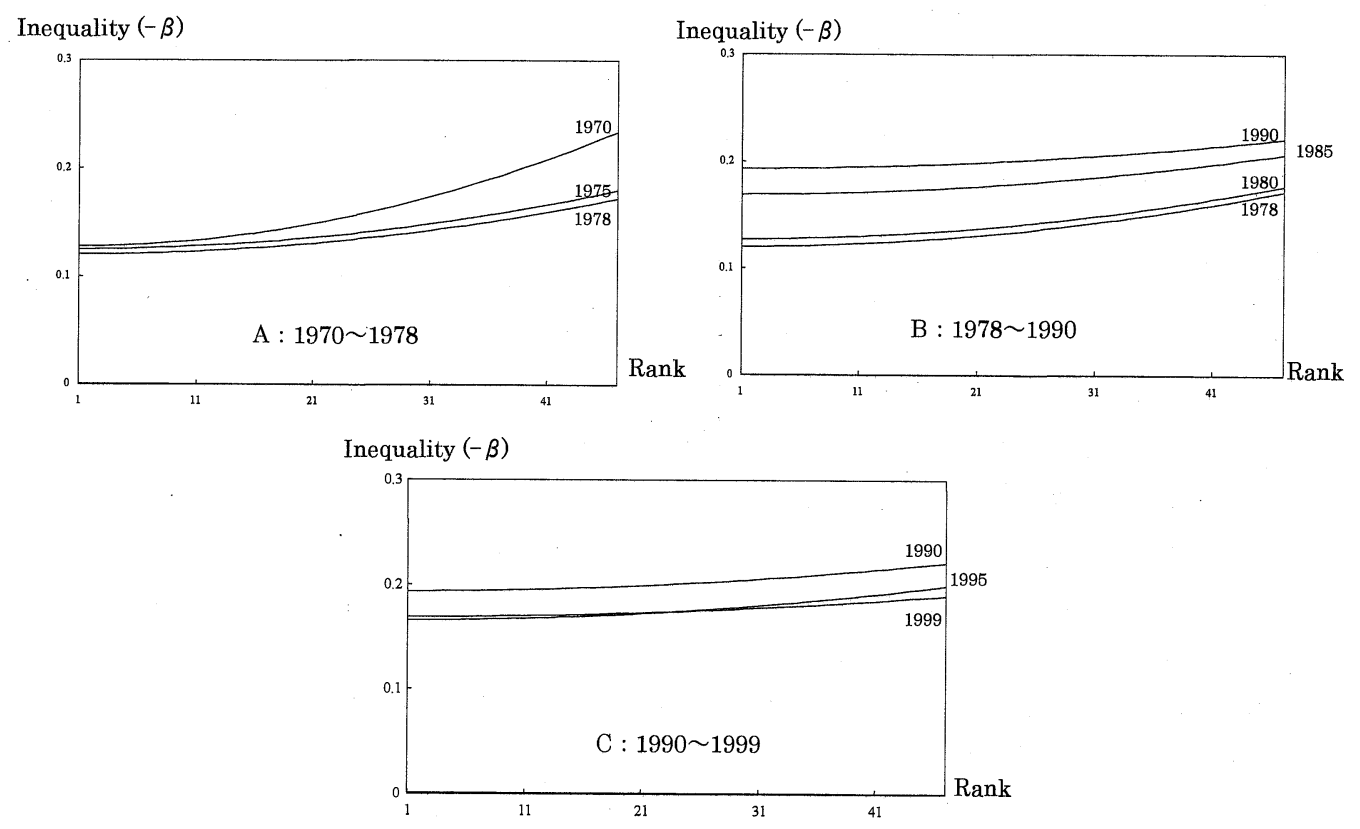

Fig. 7 Changes of inequality with respect to rank in Japan

arbitrarily selected $r$. The general positions of the curves in Fig. 7 indicate that inequality throughout the ranks has declined between 1970 and 1978 and has increased between 1978 and 1990, but has decreased again after 1990. Changes in position are also accompanied by changes in slope. In particular, from 1970 to 1975, the inequality at low ranks has decreased at a greater rate than that at high ranks; and from 1978 to 1990, inequality has increased at 


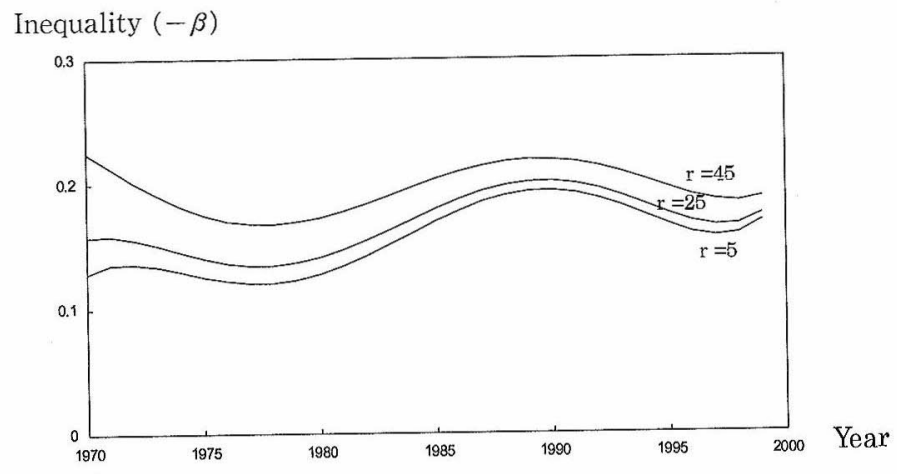

Fig. 8 Changes of inequality with respect to time in Japan

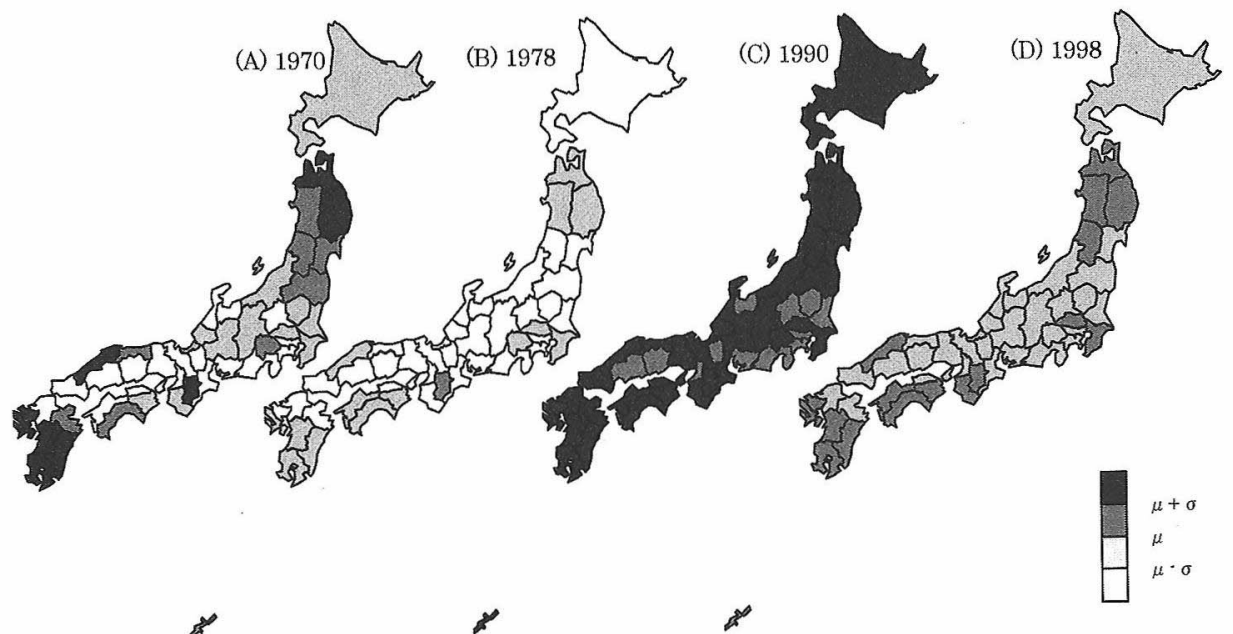

Fig. 9 Spatial variations of inequality in Japan

Note: $\mu$ is average pooled estimates of $-\beta$ from all years; $\sigma$ is standard deviation pooled estimates of $-\beta$ from all years.

both low and high ranks, but more so at high ranks.

Such trends can also be seen in Fig. 8. At $r=45$ (low rank), the inequality over time has declined sharply until 1978 and increased gradually between 1978 and 1990, then decreased again after 1990. At $r=5$ and $r=25$, inequality has generally decreased slowly until 1978 and increased sharply between 1978 and 1990, then decreased again after 1990. Moreover, for $r=5$ and $r=25$ the inequality shows an increasing tendency after 1997.

Figure 9 portrays the spatial variations of inequality and associates the above findings with individual prefectures. Shading classes in Fig. 9 are determined by dividing the regions into four portions on the basis of an average $(\mu=0.169)$ and standard deviation $(\sigma=0.026)$ pooled estimates from all years, like in Fig. 6. In the case of Japan, the maps for 1970, 1978, 1990 and 1998 are selected for discussion. Figure 9 focuses on not merely changes of the inequality of individual prefectures but also on the spatial flows of factors of production.

Figure 9A shows that in 1970 most the prefectures in Western Japan national axial zone were in the low inequality category, including Tokyo, Kanagawa, Shizuoka, Aichi, Mie, 
Kyoto, Osaka, Hyogo, Okayama, Hiroshima and Fukuoka, which depicts the consolidation of the traditional core and the intensification of polarization. The peripheral prefectures in the Tohoku and Kyushu (except Fukuoka), on the other hand, were in high and high/moderate inequality categories.

Figure 9B depicts the remarkable decrease of inequality levels in Tohoku and Kyushu prefectures in 1978. Their income growth which signified polarization reversal reduced the inequality between them as well as the inequality between them and the former cores.

Figure 9C shows that by 1990 the inequality levels had increased in most parts of the country, as the process of spatial restructuring selectively boosted the income of some prefectures. All prefectures were in high and high/moderate inequality categories. In these, some prefectures of the traditional core, that is, Tochigi, Gunma, Ibaraki, Tokyo, Kanagawa, Toyama, Shizuoka, Aichi, Shiga, Osaka, Okayama and Hiroshima have lower inequality levels than others.

Figure 9D indicates that in 1998 though the trend of the decrease of inequality in most part of prefectures is obvious, prefectures in the northern part of Tohoku, Saitama, Chiba, Wakayama, Nara, prefectures in Shikoku (except Kagawa), Shimane, prefectures in Kyushu (except Fukuoka, Oita) and Okinawa still cannot get out of the comparatively high inequality category. A comparison of 1998 with 1970 suggests that overall spatial pattern is unchanged though the intensity of inter-regional inequality has become low.

\section{Summary and Conclusions}

Based on Amos' Augmented inverted-U hypothesis that is derived from Williamson's Inverted-U, this paper demonstrates the patterns of regional inequality in Korea and Japan, where economic development levels differ, by applying the coefficient of variation and Theil entropy measure. Through a decomposition of Theil entropy measure and the expansions of rank-size function, the spatial dynamic variations of regional inequality in Korea and Japan can be clarified. The results of such analyses can be summarized as follows.

First, in the case of Korea, regional inequality, though continuously decreasing till 1996, has been increasing conspicuously since 1996, which means that Korea has passed polarization reversal phase and entered into spatial restructuring phase. Comparing this with the similar preceding results for Japan and US, this can be ascribed to the shift of Korea's leading economy from material type manufacturing industry to the high-tech industry represented by electronics industry.

The results of analysis using the decomposed Theil entropy measure indicate that since 1990s the inequality between regional groups has decreased rapidly while inequality within regions has increased greatly. Particularly, in Southeast, the inequality among cities and provinces is severe.

An examination of the expansion of rank-size function shows that systemic inequality variations are connected with spatial flows of production factors that accompany the growth or decline of regions. The general characteristics of spatial variations are that economic declines in major cities, such as Incheon, Busan, Daegu are contrasted starkly with the income increases in West Coast area, such as Chungnam, Jeonnam, and continuous growth in Chungbuk, Gyeongbuk, Gyeongnam. 
Next, in the case of Japan, rapid decrease of inequality till 1975 turned around from 1978 to 1990 on the path of increase, which reached its peak in 1990 and then tended to decrease again after 1990. We can conclude that since 1978, Japan had entered into spatial restructuring phase from polarization reversal phase, which can be interpreted as industrial reconstruction caused by the shift of Japan's leading industry from material type manufacturing to the high-tech since late 1970s, accompanied by the shifting era of Japan's economy from high speed to stable growth.

The analyses using decomposed Theil entropy measure demonstrate clearly that the inequality within regional groups is higher than that between the regional groups. Within the regional groups, the inequality among the Kanto prefectures has the highest level, while that among the Kinki prefectures has the $2^{\text {nd }}$ highest level.

The general characteristic of spatial variations in Japan by the analysis results of the expanded rank-size function is its comparatively unchanged overall spatial pattern, though the intensity of inter-regional inequality has become low. Obvious as trend of systemic inequality decrease stimulated by economic growths of low income prefectures is, prefectures in the northern part of Tohoku, Saitama, Chiba, Wakayama, Nara, prefectures in Shikoku (except Kagawa), Shimane, prefectures in Kyushu (except Fukuoka, Oita) and Okinawa still cannot get out of the comparatively high inequality category.

This paper uses the single measure of per capita GRDP to analyze regional inequality variations, which, in fact, are closely related to many important factors, such as employment, income, population etc. Therefore, many other economic indices and analysis methods are necessary for a more comprehensive investigation of such cases.

Related with this research, there remain two works to be developed: (1) identification of the factors generating differentials of income among regions and (2) derivation of policy implications based on the above analysis.

\section{Acknowledgement}

An earlier version of this paper was presented at the $40^{\text {th }}$ Annual Meeting of the Japan Section of the RSAI (Regional Science Association International) 1-2 November 2003, at the University of the Ryukyus Okinawa, Japan. I would like to thank Akio Matsumoto, J. Barkley Rosser, Jr, Mari Morino, Lily Kiminami, Toshiharu Ishikawa and Masashi Kaneda for helpful comments.

\section{Notes}

1) Change of regional inequality originates in movement of the factors of production by economic development. The increase in regional inequality is explained by concentration of factors of production in selected regions of a nation; and the decrease in regional inequality is explained by diffusion of factors of production. Explanations for the inverted-U hypothesis in regional inequality have been strongly influenced by neoclassical logic, which emphasizes the tendency toward equilibrium as the factor market adjustment mechanism evens out regional inequality.

2) Neoclassical logic cannot give a reasonable explanation of increases in regional inequality at advanced phases of development, which, according to the existing literature, is ascribed to changes of industrial structure like the shift from material type manufacturing industry, such as heavy chemical industries, to the high-tech industry represented by electronics industry (Nakamura and 
Tabuchi [12], Fan and Casetti [6]).

3) Fukuchi and Nobukuni [7] shows that regional inequality increases if the economic growth rate becomes high beyond a certain level in Japan. Tanioka [13] identifies that there is positive correlation between regional income inequality and economic growth rate. Tanioka and Yamada [15] analyzed trends and causes of interregional disparities in Japan after the World War II. They suggested that Williamson's inverted- $U$ hypothesis is not applied in Japan. Hur [8] attempted to explain the inverted-U hypothesis based on the study of the relationship of industrialization and urbanization. Kim and Park [9] suggested that it is the best way for balanced regional growth in Korea to raise the interregional mobility of production factors, especially the capital stock. Yim [17] argued that IMF crisis which is as an accelerating trigger of spatial reconfiguration in Korea, increased regional inequality.

4) Although Korea has 16 major cities \& provinces as of 2003, in this paper 13 major cities \& provinces are used for empirical analysis. Daejeon was promoted to major city in 1989, Gwangju in 1986 and Ulsan in 1998, but this paper starts its analysis from 1985, thus these three cities are counted as provinces before being promoted.

5) The empirical analysis is mainly concerned with inter-prefecture (or inter-province) income inequality, which is the most appropriate scale of analysis that reflects differentials of income due to processes of regional growth and decline such as polarization, polarization reversal and the recent spatial restructuring (Fan \& Casetti [6]).

6) Byun [3] proposed that Korea had entered into the polarization reversal phase which means decrease of regional inequality after the end of the 1960s, and still existed in the polarization reversal phase in 1992. Tanioka [14] showed that regional inequality in Japan decreased from 1961 to 1975 , then stable inequality was maintained from 1975 to 1984 , which increased again after 1984. These findings indicate that regional inequality in Japan entered into the polarization reversal phase after 1961, and moved into spatial restructuring after the second half of the 1970s. Based on these researches, this paper selects a different analysis period for the two countries to focus on the process moving into the spatial restructuring phase from the polarization reversal phase.

7) Amos' Augmented Inverted-U that modified Williamson's Inverted-U is shown in Fig. A. There are two paths that can be chosen after C, i.e. stabilization and increase. The alternative path $\mathrm{CD}$ indicates stable, unchanging regional inequality, while the second path $\mathrm{CE}$ stands for the increase of regional inequality once the Inverted- $U$ pattern has been completed. In this case, the simple increase-decrease Inverted- $U$ pattern is replaced by a pattern of increase-decrease- increase. This path $\mathrm{CE}$ is just the portion developed by Amos (Amos [2], Byun [3]). Path ABC in Fig. A demonstrates the process of polarization and polarization reversal, and path $\mathrm{CE}$ the process of spatial restructuring.

8) This figure is describing the pattern of inter-regional inequality based on Amos' augmented

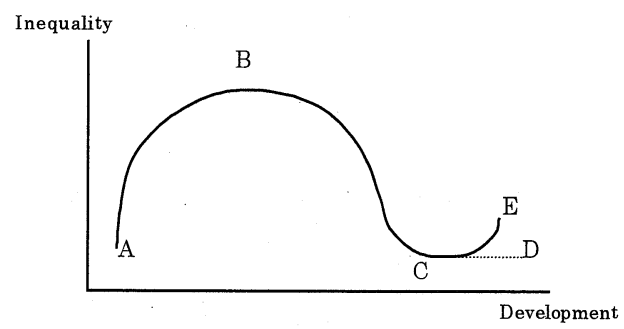

Fig. A Relationship between inequality and level of development 
inverted-U.

9) In this paper, expansion of rank-size function is performed based on research of Fan and Casetti [6].

10) This hypothesis testing approach means to test the hypothesis that parameters associated with the newly added time variables are zero. If the hypothesis is not rejected, lower degree of temporal expansions than the one that is being tested will be chosen. Otherwise, the hypothesis will be repeated for the next higher degree.

11) The degree of temporal expansion in Korea is chosen by the following hypothesis testing approaches.

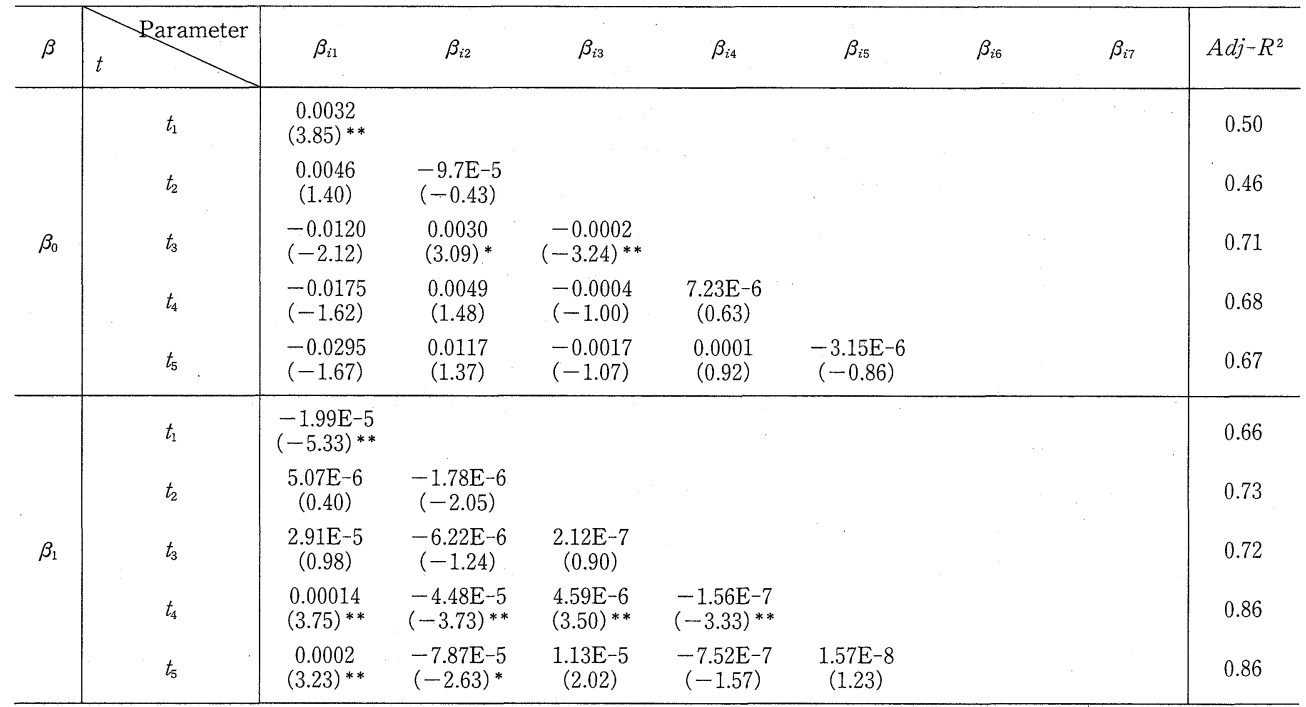

Note: ${ }^{* * *}$ significant at the $5 \%$ and $1 \%$ level respectively. $t$-values are in parentheses.

12) The degree of temporal expansion in Japan is chosen by the following hypothesis testing approaches.

\begin{tabular}{|c|c|c|c|c|c|c|c|c|c|}
\hline$\beta$ & Parameter & $\beta_{i 1}$ & $\beta_{i 2}$ & $\beta_{i 3}$ & $\beta_{i 4}$ & $\beta_{i 5}$ & $\beta_{i 6}$ & $\beta_{i 7}$ & $A d j-R^{2}$ \\
\hline \multirow{6}{*}{$\beta_{0}$} & $t_{1}$ & $\begin{array}{c}0.0003 \\
(0.85)\end{array}$ & & & & & & & - \\
\hline & $\mathrm{t}_{2}$ & $\begin{array}{c}0.0012 \\
(0.97)\end{array}$ & $\begin{array}{c}-3.09 \mathrm{E}-5 \\
(-0.78)\end{array}$ & & & & & & - \\
\hline & $\mathrm{t}_{3}$ & $\begin{array}{c}0.0126 \\
\left(8.25^{* *}\right)\end{array}$ & $\begin{array}{c}-0.0010 \\
\left(-8.37^{* *}\right)\end{array}$ & $\begin{array}{l}2.32 \mathrm{E}-5 \\
\left(8.24^{* *}\right)\end{array}$ & & & & & 0.71 \\
\hline & $\mathrm{t}_{4}$ & $\begin{array}{c}0.0164 \\
\left(5.78^{* *}\right)\end{array}$ & $\begin{array}{c}-0.0016 \\
\left(-4.03^{* *}\right)\end{array}$ & $\begin{array}{c}5.62 \mathrm{E}-5 \\
\left(2.63^{*}\right)\end{array}$ & $\begin{array}{c}-5.7 \mathrm{E}-7 \\
(-1.56)\end{array}$ & & & & 0.72 \\
\hline & $t_{5}$ & $\begin{array}{l}0.0027 \\
(0.82)\end{array}$ & $\begin{array}{c}0.0019 \\
\left(2.60^{* *}\right)\end{array}$ & $\begin{array}{c}-0.0003 \\
\left(-4.27^{* *}\right)\end{array}$ & $\begin{array}{l}1.25 \mathrm{E}-5 \\
\left(5.01^{* *}\right)\end{array}$ & $\begin{array}{l}-1.80 \mathrm{E}-7 \\
\left(-5.27^{* *}\right)\end{array}$ & & & 0.87 \\
\hline & $t_{6}$ & $\begin{array}{l}0.0006 \\
(0.12)\end{array}$ & $\begin{array}{l}0.0027 \\
(1.67)\end{array}$ & $\begin{array}{l}-0.0004 \\
(-1.81)\end{array}$ & $\begin{array}{c}1.98 \mathrm{E}-5 \\
(1.45)\end{array}$ & $\begin{array}{c}-4.03 \mathrm{E}-7 \\
(-0.98)\end{array}$ & $\begin{array}{c}2.57 \mathrm{E}-9 \\
(0.55)\end{array}$ & & 0.86 \\
\hline \multirow{6}{*}{$\beta_{1}$} & $t_{1}$ & $\begin{array}{l}3.57 \mathrm{E}-7 \\
\left(5.25^{* *}\right)\end{array}$ & & & & & & & 0.48 \\
\hline & $\mathrm{t}_{2}$ & $\begin{array}{l}1.01 \mathrm{E}-6 \\
\left(4.27^{* *}\right)\end{array}$ & $\begin{array}{c}-2.24 \mathrm{E}-8 \\
\left(-2.85^{* *}\right)\end{array}$ & & & & & & 0.58 \\
\hline & $\mathrm{t}_{3}$ & $\begin{array}{l}2.56 \mathrm{E}-6 \\
\left(5.47^{* *}\right)\end{array}$ & $\begin{array}{c}-1.59 \mathrm{E}-7 \\
\left(-4.19^{* *}\right)\end{array}$ & $\begin{array}{l}3.14 \mathrm{E}-9 \\
\left(3.65^{* *}\right)\end{array}$ & & & & & 0.71 \\
\hline & $t_{4}$ & $\begin{array}{l}4.62 \mathrm{E}-6 \\
\left(6.00^{* *}\right)\end{array}$ & $\begin{array}{l}-4.91 \mathrm{E}-7 \\
\left(-4.44^{* *}\right)\end{array}$ & $\begin{array}{l}2.12 \mathrm{E}-8 \\
\left(3.66^{* *}\right)\end{array}$ & $\begin{array}{l}-3.11 \mathrm{E}-10 \\
\left(-3.14^{* *}\right)\end{array}$ & & & & 0.79 \\
\hline & $t_{5}$ & $\begin{array}{l}8.27 \mathrm{E}-6 \\
\left(9.12^{* *}\right)\end{array}$ & $\begin{array}{l}-1.43 \mathrm{E}-6 \\
\left(-7.08^{* *}\right)\end{array}$ & $\begin{array}{l}1.10 \mathrm{E}-7 \\
\left(6.09^{* *}\right)\end{array}$ & $\begin{array}{l}-3.77 \mathrm{E}-9 \\
\left(-5.47^{* *}\right)\end{array}$ & $\begin{array}{c}4.77 \mathrm{E}-11 \\
\left(5.05^{* *}\right)\end{array}$ & & & 0.89 \\
\hline & $t_{6}$ & $\begin{array}{l}9.12 \mathrm{E}-6 \\
\left(6.62^{* *}\right)\end{array}$ & $\begin{array}{c}-1.75 \mathrm{E}-6 \\
\left(-3.98^{* *}\right)\end{array}$ & $\begin{array}{l}1.56 \mathrm{E}-7 \\
\left(2.65^{*}\right)\end{array}$ & $\begin{array}{c}-6.79 \mathrm{E}-9 \\
(-1.81)\end{array}$ & $\begin{array}{c}1.40 \mathrm{E}-10 \\
(1.24)\end{array}$ & $\begin{array}{c}-1.06 \mathrm{E}-12 \\
(-0.82)\end{array}$ & & 0.89 \\
\hline
\end{tabular}


Note: ${ }^{* * *}$ significant at the $5 \%, 1 \%$ level respectively. $t$-values are in parentheses.

\section{References}

[1] Alonso, W., 1980, "Five Bell Shapes in Development," Papers of Regional Science Association, 45, 5-16.

[2] Amos, O.J., 1988, "Unbalanced Regional Growth and Regional Income Inequality in the Latter Stage of Development," Regional Science and Urban Economics, 18, 549-566.

[ 3 ] Byun, B., 1999, "A Comparative Study of Regional Inequality Patterns in Korea and the United States," The Journal of Korea Planners Association, 34 (2), 157-165.

[4] Coughlin, C.C. and T.B. Mandelbaum, 1988, "Why have State Per Capita Incomes Diverged Recently ?" Review, the Federal Bank of St. Louis, 70 (5), 24-36.

[5] Economic and Social Research Institute Cabinet Office, Government of Japan, 2002, Annual Report on Prefectural Accounts, Tokyo: The Printing Bureau.

[6] Fan, C.C. and E. Casetti, 1994, "The Spatial and Temporal Dynamics of US Regional Income Inequality, 1950-1989," The Annals of Regional Science, 28, 177-196.

[7] Fukuchi, T. and M. Nobukuni, 1970, "An Econometric Analysis of National Growth and Regional Income Equality,” International Economic Review, 11(1), 84-100.

[ 8 ] Hur, J., 1989, "The Dynamic Pattern of Regional Inequalities and Testing of a Hypothesis," The Journal of Korea Planners Association, $24(2), 69-77$.

[9 ] Kim, Y., and J. Park, 1996, "National Growth and Regional Income Difference in Korea," Journal of the Korean Regional Development, 8(2), 35-48.

[10] Korea National Statistical Office, 2002, Regional Statistics Yearbook, Daejeon: National Statistical Office.

[11] Kuznets, S., 1955, "Economic Growth and Income Inequality," The American Economic Review, 45, $1-28$.

[12] Nakamura, R., and T. Tabuchi, 1996, Urban and Regional Economics, Tokyo: Yuhikaku.

[13] Tanioka, K., 2000, "Statistical Analysis of Economic Growth and Regional Disparity," The Review of the Osaka University of Commerce, 116, 321-344.

[14] Tanioka, K., 2001, "Study of Regional Income Disparity and Population Movement," Journal of Region and Society, 4, 39-59.

[15] Tanioka, K., and H. Yamada, 2000, "Trends and Causes for Japanese Inter-regional Disparities after the World War II," Journal of Applied Regional Science, 5, 149-160.

[16] Williamson, J.G., 1965, "Regional Inequality and the Process of National Development: a Description of Patterns," Economic Development and Cultural Change, 13, 3-45.

[17] Yim, S., 2002, "Economic Restructuring and Regional Disparity after the IMF Crisis in Korea," Journal of the Korean Association of Regional Geographers, 8(4), 513-528.

[18] Zipf, G. K., 1949, Human Behavior and the Principle of Least Effort, Cambridge, Massachusetts: Addison Wesley. 